\title{
Effects of dextran sulphate sodium on intestinal epithelial cells and intestinal lymphocytes
}

\author{
J Ni, S-F Chen, D Hollander
}

\begin{abstract}
Background and Aims-The effects of dextran sulphate sodium (DSS) on mouse intestinal epithelial cells and intraepithelial lymphocytes were analysed to investigate the mechanism by which DSS induces colitis and tumours in mice. Cytotoxicity of DSS towards intestinal epithelial cells and intestinal intraepithelial lymphocyte hybridomas or fresh intestinal intraepithelial lymphocytes seems to have concentration, time, and cell type dependency with increasing concentrations and time causing increased cytotoxicity.

Results-Integrin $\alpha 4$ expression was marginally down regulated by $0.5 \%$ of DSS, while $\alpha M 290$ expression was up regulated. DSS inhibits the binding of $9 \cdot 1 \gamma \delta$ cells to both extracellular matrix (ECM) and epithelial cells. Conversely at high concentrations it increases binding to all ECM except poly-L-lysine. Various cytokines including TGF $\beta$, interleukin 2 , and tumour necrosis factor $\alpha$ as well as prostaglandin alter the expression of the integrin $\alpha 4$ and $M 290$ subunits at the cell surface, and also alter the adhesion of 9.1 $\gamma \delta$ cells to epithelial monolayers. The expression of a large number of cell adhesion molecules expressed on intraepithelial lymphocytes is affected by a combination of the abundant gut cytokine TGF $\beta$ and DSS, suggesting that DSS induced colitis may ultimately arise from a combination of gut cytokine and DSS. DSS also triggers intraepithelial lymphocyte aggregation on all ECM coated plate tested.
\end{abstract}

Conclusions-These data suggest that the potential roles of DSS induced colitis may be: (a) direct cytotoxicity; (b) interference with the normal interaction between intestinal lymphocytes, epithelial cells, and ECMs; (c) aberrant modulation of the expression of the integrin $\beta 7$ receptors, other cell receptors, and their functions.

(Gut 1996; 39: 234-241)

I, Division of

Gastroenterology,

Department of

Medicine, University

of California, Irvine,

USA

$\mathrm{Ji}$

S-F Chen

D Hollander

Correspondence to:

Dr J Ni, Human Genome

Sciences, 9620 Medical

Center Drive, Suite 300

Rockville, MD 20850-3338,

USA.

Accepted for publication

27 February 1996 ntraepithelial lymphocytes (IELs) reside on basolateral surface of the intestinal epit ial cells. IELs are part of the mucosal immu defence mechanisms, ${ }^{1}$ which are poised respond to antigenic challenges from the intestinal lumen. The immune functions of IELs depend in part on a new family of integrin receptors, the $\beta 7$ integrins, ${ }^{23}$ which are expressed mostly on intestinal IELs and lamina propria lymphocytes. The integrin $\beta 7$ subunit associates with at least two alternative $\alpha$ subunits. The first is called $\alpha \mathrm{HML}-1$ or $\alpha^{\text {IEL }}$ or $\alpha^{\mathrm{E} 4}$ in humans or $\alpha \mathrm{M} 290$ in mice. ${ }^{5}$ The second $\alpha$ subunit of the $\beta 7$ integrins is called $\alpha 4 .^{6}$ Although the HML-1 $\beta 7$ integrin can be induced on peripheral blood lymphocytes by activation $^{78}$ and is expressed on some tumours, ${ }^{9}$ its predominance in vivo on intraepithelial and lamina propria lymphocytes suggests that the HML-1 $\beta 7$ receptor interacts mostly with ligands in the intestinal epithelium such as E-cadherin. ${ }^{10}$ It could be crucial for the immunological defensive functions of IELs, including cell adhesion, activation, differentiation, and cytotoxicity.

The aetiology of inflammatory bowel disease (IBD) and colorectal carcinoma, which can subsequently arise as a complication, is unknown. Several studies suggest a central role for immunological mechanisms in the pathogenesis of IBD. It is established that colorectal carcinoma can develop as a complication of longstanding ulcerative colitis. Therefore, to understand the mechanism of IBD and cancer development, and its prevention and treatment it is important to develop an experimental model of IBD that could progress to cancer. A model of experimental colitis and colorectal carcinoma induced in mice by the feeding of dextran sulphate sodium (DSS) was developed recently in our laboratory. This model was first successfully established in rats and hamsters by other investigators. ${ }^{11}$ These investigators showed that colonic cancer can develop after prolonged existence of ulcerative lesions formed by exposing the colonic mucosa to DSS. The colitis and neoplasias had histological similarities to those in humans. ${ }^{1011}$ However, the mechanisms by which DSS induced colitis and colonic tumours are unknown.

DSS is a polyclonal B and T cell activator..$^{12} 13$ The binding of sulphated glycans, such as DSS, is believed to play an important part in regulating or mediating the functions of a number of cell adhesion molecules, ${ }^{14}{ }^{15}$ including $\mathrm{CD} 2^{14}$ and CD4, as well as growth factors and extracellular matrix (ECM) proteins. A natural ligand for the $T 11_{2}$ epitope of CD2 was identified as a sulphated carbohydrate. ${ }^{14}$ The binding of P-selectin to neutrophils is inhibited by sulphated glycans such as heparin and dextran sulphate, suggesting that the sulphated glycan binding site and the neutrophil receptor binding site on $\mathrm{P}$-selectin are either identical or proximal. ${ }^{16}$ Binding of $\mathrm{L}$ or $\mathrm{P}$-selectins to either $S L e^{x}$ or $S L e^{a}$ is inhibited by dextran sulphate. 
It was suggested that dextran sulphate interact with epidermal growth factor (EGF) domains or complement regulatory sequence repeats, thereby including conformational changes of selectins. ${ }^{17}$ The integrin $\beta 7$ subunit has four cysteine rich EGF-like repeated domains, which could interact with DSS. DSS also interacts with fibronectin and strengthens the binding of fibronectin to collagen. ${ }^{18}$ DSS could interact with these molecules by ionic interaction or intramolecular perturbation, or both, or by direct binding. DSS may interfere with normal $\beta 7$ integrin functions or expression, leading to exaggerated or uncontrolled immune responses to a variety of environmental antigens and, consequently, to a cascade of events, including lymphocyte proliferation, cytokine release, and secondary recruitment of auxiliary effector cells such as neutrophils. Neutrophil products could amplify the immune response and cause excessive non-specific or 'innocent bystander' injury.

To delineate the potential mechanisms of DSS induced colitis and the role of $\beta 7$ integrins, we studied the expression of $\beta 7$ receptors and properties of IEL hybridomas (IELH), and the effects of DSS on interaction between intestinal epithelial cells and lymphocytes or ECM proteins.

\section{Methods}

Cell lines, monoclonal antibodies, cytokines, and other reagents

Rat ileum epithelial cell line, IEC-18; mouse rectal carcinoma cell line, CMT-93; mouse lymphoma cell line, BW5147; rat hybridoma cell line secreting mAb to murine $\alpha 4$ integrin chain (R1-2); VCAM-1 (M/K - 1.9), CD44 or Pgp-1 (KM 201), CD45RB (MB23G2), ICAM-1 or CD54 (YN1/1.7.4), LFA-1 $\alpha$ or $\alpha \mathrm{L}$ or CD11a (M17/4.4.11.9), MAC-1 $\alpha$ or $\alpha M$ (M1/70.15.11.5), LFA-1 or CD11a/CD18 or $\alpha \mathrm{L} \beta 2$ (FD441.8), CD4 (GK1.5), dendritic cell (33D1), common leucocyte antigen or CD45 (M1/89.18.7); hamster antimouse CD11c or $\alpha \mathrm{X}$ (N418); were all obtained from American Type Culture Collection, Rockville, USA. 9·1 $\gamma \delta$ IELH were generously supplied by $\mathrm{Dr}$ Mitchell Kronenberg. It was made by fusing freshly isolated IELs from the CD1 strain of mice that were transgenic for a rearranged $\mathrm{V} \gamma 1 \cdot 1 \mathrm{~J} \gamma 4 \mathrm{C} \gamma 4$ gene to a TCR $\alpha-\beta$-variant of BW5147. A rat hybridoma producing $\mathrm{mAb}$ to $\alpha M 290$ (M290) ${ }^{5}$ was generously supplied to us by Dr Peter Kilshaw from Cambridge, UK. Interleukin (IL) 2, ILA, IL7 are gifts from Immunex, Seattle, Washington. Tumour growth factor (TGF) $\beta 1$, and tumour necrosis factor (TNF) $\alpha$ were purchased from $R$ and $D$ Systems; DSS, MW $40000-50000$, was purchased from United States Biochem Corp and prostaglandin $\mathrm{E}_{2}$ was purchased from Sigma.

\section{In vitro $M T T$ cell adhesion assay}

The MTT [3(4,5-dimethylthiazoyl-2-yl)2,5 diphenyl-tetrazolium bromide] assay ${ }^{19-23}$ has been modified to detect the adhesion of unstimulated and stimulated IELH or IELs to a rat intestinal epithelial cell line (IEC-18) or mouse rectal carcinoma cells (CMT-93 or ECM. Briefly, 96 well plates were treated with poly-Llysine (approximate molecular weight 400000 , Sigma), fibronectin, laminin (GIBCO BRL), and ProNectin F (protein polymer, a genetically engineered high molecular weight protein polymer incorporating multiple copies of the RGD cell attachment site of human fibronectin) at $0 \cdot 1$ $\mathrm{mg} / 1 \mathrm{ml}$ in phosphate buffered saline (PBS), 40 $\mu \mathrm{l} /$ well for two hours. The plates were then washed twice with PBS and incubated with $0 \cdot 1$ $\mathrm{ml}$ of $1 \%$ bovine serum albumin in PBS for one hour, and washed twice more with PBS. Plates were covered with parafilm and were stored at $4^{\circ} \mathrm{C}$. Adherent cells were harvested from exponential phase cultures by trypsinisation, counted, and plated in 96 well flat bottomed microtitre plates $\left(1-2 \times 10^{4}\right.$ cells in $100 \mu \mathrm{l} /$ well $)$ for two to three days. Some $2 \times 10^{5}$ of either unstimulated or stimulated (for 20 hours) IELH cells (in $200 \mu \mathrm{l}$ ) were added to each well having confluent IEC-18, and CMT-93 monolayers or coated with ECM; in the presence or absence of various concentrations of DSS or mAbs. The unbound cells were gently removed by washing three times with $100 \mu$ l of PBS. The number of adherent cells was measured by the MTT assay. The assay was performed by the addition of 20 $\mu l$ of MTT. After three hours of incubation, $0 \cdot 1$ $\mathrm{ml}$ of DMSO was added to each well and mixed gently. The absorbence at $570 \mathrm{~nm}$ was recorded by an ELISA reader. The OD570 is directly proportional to the number of living cells in the wells. The specific adhesion and inhibition of adhesion was calculated as described in each Figure legend. Experiments were done at least in triplicate.

Cytotoxicity assays by measuring $M T T$ reduction and trypan blue exclusion

Various concentrations of DSS were incubated with IEC-18 or CMT-93 cells $\left(2 \times 10^{4} /\right.$ well, plated 24 hours earlier) as well as IELH for 30 minutes, one hour, four hours, and 20 hours. The cytotoxic effects were measured by MTT assay and the percentage of cytotoxicity was calculated as: 100 $\mathrm{OD}_{\text {experimental }} / \mathrm{OD}_{\text {control }} \times 100 . .^{19-23}$ The cytotoxic effects were also measured by trypan blue exclusion assay and the percentage of cytotoxicity was calculated as: trypan blue $(+)$ cell number $_{\text {experimental }} /$ total cell number $\times 100$.

\section{Aggregation assay}

IELH and IELs were incubated with ECM coated plates in the presence of various concentrations of DSS or mAbs, or both, to $\alpha 4$ or $\alpha M 290$ (1:10) for various times. The aggregation was scored as described by Ruegg et al ${ }^{24}$ with 0 indicating less than $10 \%$ aggregation, $1=10-20 \%, 2=20-40 \%, 3=40-60 \%, 4=60$ $80 \%, 5=80-100 \%$.

Flow cytometry analysis

Cell surface expression of the leucocyte antigens and cell adhesion molecules was analysed with a 
FACScan using the Lysis II program and calibration with the AutoCOMP program. ${ }^{19-21}$ Unstimulated and TGF $\beta$ (5 ng/'ml), $0.5 \%$ DSS, $\mathrm{PGE}_{2}(3 \mu \mathrm{M}), \mathrm{TGF} \beta(5 \mathrm{ng} / \mathrm{ml}), \mathrm{TNF} \alpha$ $(100 \mathrm{U} / \mathrm{ml})$, and IL2 $(100 \mathrm{U} / \mathrm{ml})$ stimulated (one or 20 hours) IELH $\left(0.5 \mathrm{ml}, 10^{6} / \mathrm{ml}\right)$ in RPMI 1640 with $5 \%$ fetal bovine serum were incubated for 30 minutes at $48 \mathrm{C}$ with various mAbs. Cells were washed twice with PBS containing $1 \%$ bovine serum albumin and $0.1 \%$ sodium azide and then incubated ( 30 minutes at $4^{\circ} \mathrm{C}$ ) with FITC labelled antirat or antihamster antibodies $(10 \mu \mathrm{l})$. The cells were washed twice before performing flow cytometry analysis. Intensities of fluorescence were determined relative to a negative control threshold set by substituting normal immunoglobulin for the primary antibody or omitting the primary antibody.

\section{Statistical analysis}

Variability of the data is expressed as the standard error of the mean (SEM). For the comparative analysis, the data were examined using an unpaired Student's $t$ test with StatWorks software. Values of $p<0.05$ were considered statistically significant.
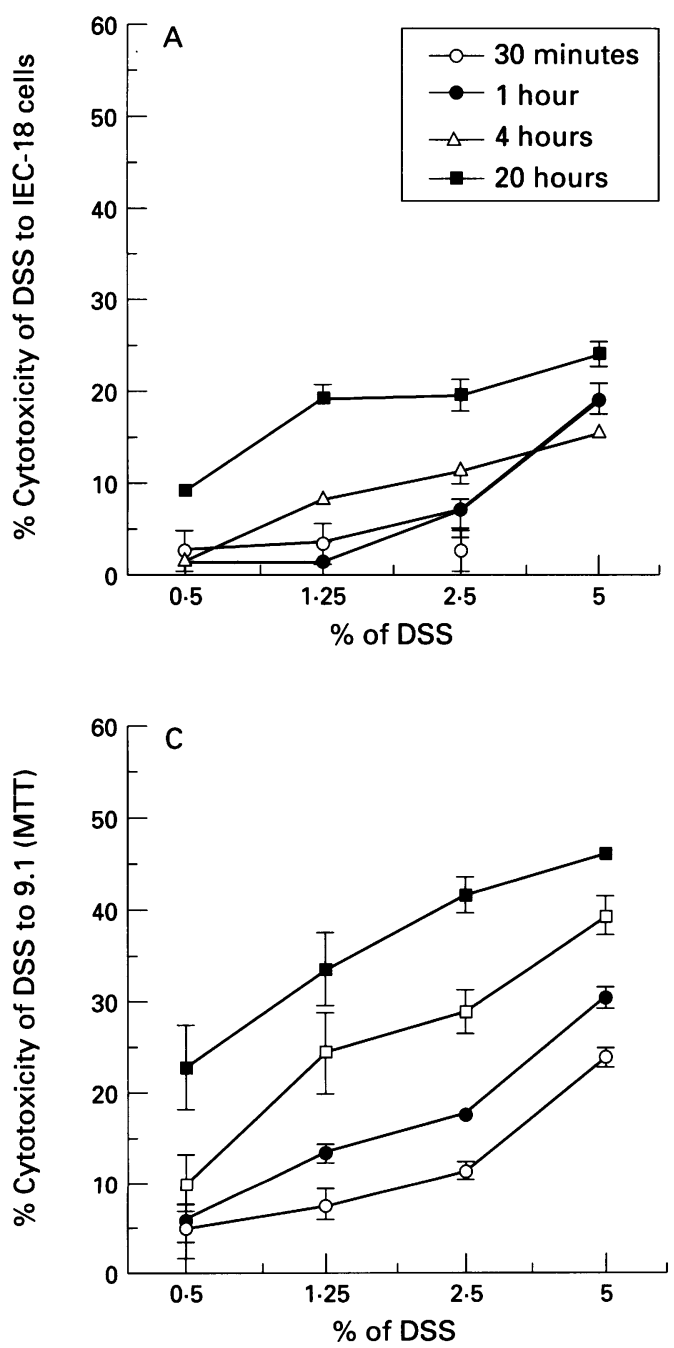

\section{Results}

Cytotoxicity of DSS to intestinal epithelial cells and lymphocytes

To delineate the mechanisms of DSS induced colitis, we studied the effects of DSS on intestinal epithelial cells and lymphocytes. Various concentrations of DSS were incubated with IEC-18 (Fig 1A), CMT-93 (Fig 1B), $9 \cdot 1 \gamma \delta$ (Fig 1C, 1D), and several other IELH cells. The cytotoxic effects were measured by both MTT (an assay of both mitochondrial functions and cell number) and trypan blue staining (an assay of both plasma membrane integrity and cell number). Direct cytotoxicity of DSS towards IEC-18, CMT-93 intestinal epithelial cells and $9 \cdot 1 \gamma \delta$ IELH or fresh IELs (not shown) seems to have both concentration and time dependency with increasing concentrations and time causing increased cytotoxicity. Within 30 minutes or one hour, $2.5 \%$ of DSS or less showed insignificant cytotoxicity to most of the cell types tested. IEC-18 cells were more resistant to the cytotoxicity of DSS than CMT-93, while IELH were more sensitive than epithelial cells, and fresh IELs were the most sensitive.
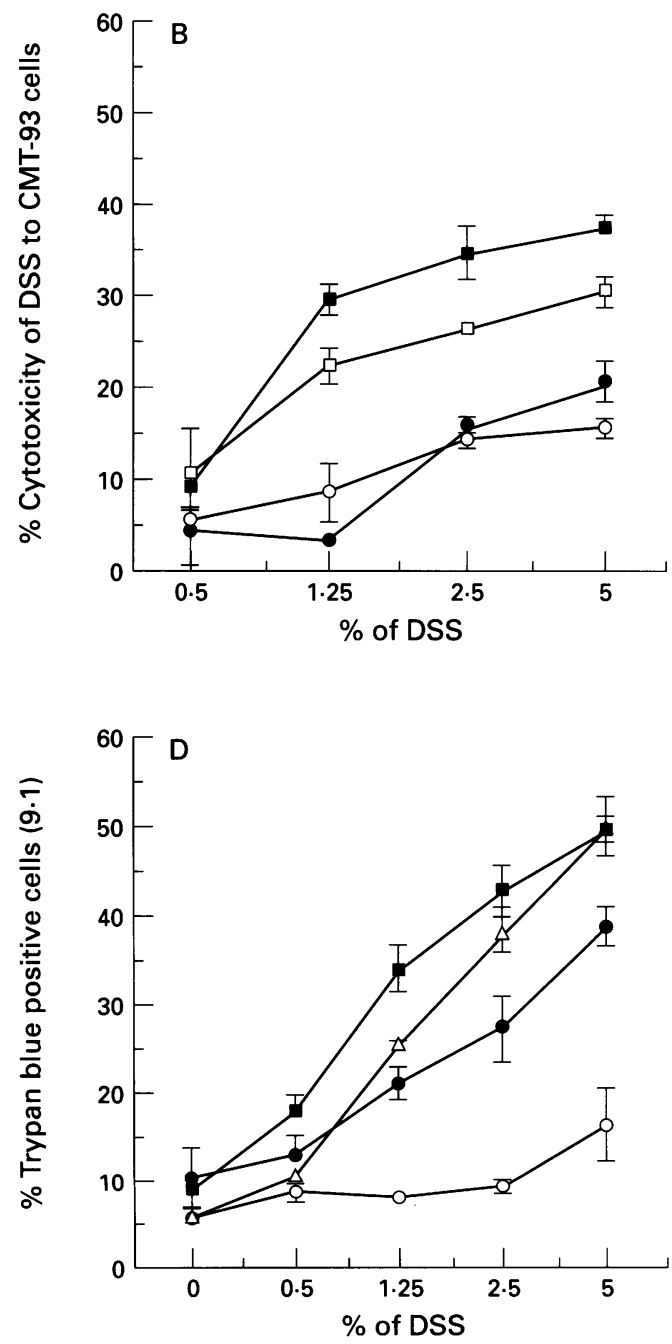

Figure 1: The cytotoxicity of DSS towards IEC-18 (A),CMT-93 (B), and $9 \cdot 1 \gamma \delta(C, D)$ cells. Various concentrations of DSS were incubated with IEC-18 cells ( $2 \times 10^{4} /$ well, plated 24 hours earlier) for 30 minutes, one, four, and 20 hours. The cytotoxic effects were measured by MTT assay $(A-C)$ and the percentage of cytotoxicity was calculated as: $100-O D_{\text {experimental }} / O D_{\text {control }} \times 100$. In $(D)$, the cytotoxic effects were measured by a trypan blue exclusion assay and the percentage of cytotoxicity was calculated as: trypan blue $(+)$ cell number $r_{\text {experimental }}$ Total cell number $\times 100$. 

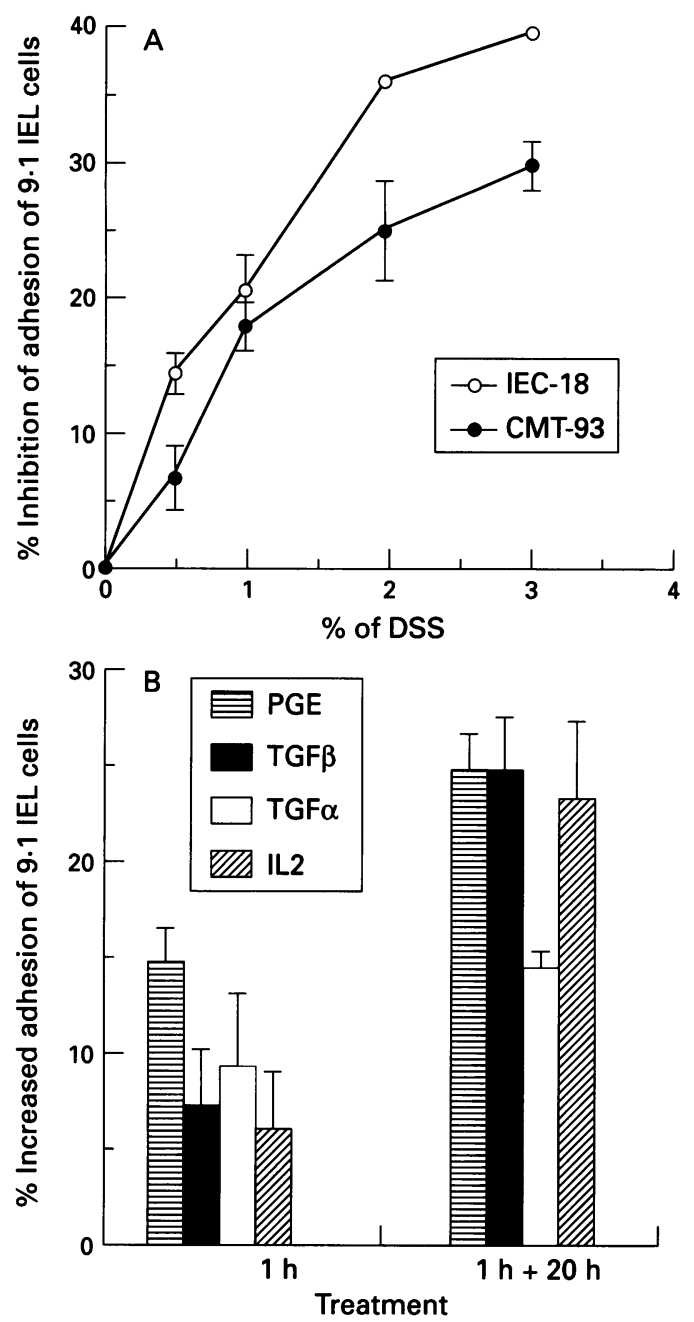

Figure 2: (A) Inhibition of adhesion of 9.1 IEL hybridoma cells to epithelial monolayers by DSS. 9.1 $\gamma \delta$ IEL hybridoma cells were incubated with IEC-18 or CMT-93 monolayers in the presence of various concentrations of DSS for 30 minutes, and then gently washed three times with $100 \mu$ l of PBS. The number of adherent cells was measured by MTT assay. The data represent the

percentage of adherent cells compared with control wells in which no DSS was added, calculated as $100-$

$O D_{\text {experimental }} / O D_{\text {control }} \times 100$. (B) Increased adhesion of 9.1 IEL hybridoma cells to IEC-18 monolayers by PGE, $T G F \beta, T N F \alpha$, and IL2. $9 \cdot 1 \gamma \delta$ cells were first incubated with PGE 2 (3 $\mu M), T G F \beta(5 \mathrm{ng} / \mathrm{ml}), T N F \alpha(100$ $\mathrm{U} / \mathrm{ml})$, and IL2 $(100 \mathrm{U} / \mathrm{ml})$ for one hour, washed with $P B S$, and then either incubated for a further 20 hours (one hour +20 hours) before adding to IEC-18 cells, or added directly to IEC-18 monolayers. After incubation for a further one hour, percentage of adherent cells was calculated as $O D_{\text {experimental }} / O D_{\text {control }} \times 100-100$.

Effects of DSS on adhesion of IELH to intestinal cells and its modulation by cytokines or $P G E_{2}$ To delineate the potential role of $\beta 7$ receptors in DSS induced colitis, we studied the effects of DSS on the interaction between intestinal epithelial cells and lymphocytes and its modulation by cytokines or $\mathrm{PGE}_{2}$. The adhesion of $9 \cdot 1 \gamma \delta$ cells (Fig 2A) to IEC-18 or CMT-93 monolayers was inhibited when cells were allowed to adhere in the presence of various concentrations of DSS for 30 minutes. In a previous study, ${ }^{21}$ we found that $\beta 7$ integrin receptors play an important part in the adhesion of IEL hybridomas and freshly isolated IELs to intestinal epithelial cells. In addition, inhibition of $\beta 7$ receptors with specific antibodies reduced the adhesion of IELs to intestinal epithelial monolayers. It is possible that the dose dependent inhibition of adhesion of IELH to epithelial cells resulted from a direct interaction between DSS and $\beta 7$ or its ligands in epithelial cells during adhesion assay.

When $9 \cdot 1 \gamma \delta$ cells were first incubated with $\mathrm{PGE}_{2}, \mathrm{TGF} \beta, \mathrm{TNF} \alpha$, and IL2 for one hour, adhesion to IEC-18 (Fig 2B) was increased by 5 to $15 \%$. After stimulation for one hour and then incubating for a further 20 hours, adhesion to IEC-18 (Fig 2B) was significantly increased (up to 15 to $30 \%$ ).

Effect of $P G E_{2}, T G F \beta, T N F \alpha, I L 2$, and DSS on 9.1 $\gamma \delta$ IELH cell surface expression of the integrin $\alpha 4$ and M290 subunit and other cell surface receptors

Cell surface expression (\% of positive cells) of the $\alpha 4$ and $\alpha M 290$ subunits was increased slightly by brief stimulation of cells with $\mathrm{PGE}_{2}$ for one hour; however, after washing away the $\mathrm{PGE}_{2}$ and incubating for a further 20 hours, the expression of the two $\alpha$ subunits decreased to basal values. The expression of $\alpha 4$ was marginally increased by stimulation of cells with TNF $\alpha$ for one hour and incubating for a further 20 hours, while expression of $\alpha \mathrm{M} 290$ was increased by stimulation of cells with $\mathrm{TNF} \alpha$ for one hour and remained increased after incubation for an additional 20 hours (Fig $3 A)$. Expression of $\alpha \mathrm{M} 290$ was also increased by stimulation of cells with TGF $\beta$, whereas $\alpha 4$ expression was slightly lowered.

When DSS and integrin subunit mAbs were added together during the detection of surface antigen, the expression of $\alpha 4$ was increased (Fig 3B), whereas, the expression of $\alpha \mathrm{M} 290$ was decreased. These data suggest that DSS directly affects interactions between cell surface receptors and their mAbs by intefering with or increasing the interactions between receptors and mAbs, as has previously been described for CD2. ${ }^{14}$ When cells were treated with DSS for one hour, washed, and incubated for an additional 20 hours, the expression of $\alpha 4$ and $\alpha M 290$ was increased, with a much more significant increase when DSS was present during the entire 20 hour incubation period (Fig 3B). These data suggest that DSS affects the expression of cell surface receptors by either inducing translocation of molecules to the cell surface, or more probably by modulating the synthesis of cell surface molecules.

As IELs of mice with DSS induced colitis are exposed to DSS and the mucosal cytokine TGF $\beta$, we sought to find out if the combination of DSS and TGF $\beta$ might have unique effects on adhesion molecules expression. Figure 4 shows that $\alpha 4$ expression was down regulated by TGF $\beta$ and $0.5 \%$ DSS, while $\alpha \mathrm{M} 290$ expression was up regulated, which is consistent with the effects seen with TGF $\beta$ alone (Fig 3A). Expression of CD11b, CD54, CD4, CD45RB, and VCAM-1 were considerably up regulated by $0.5 \%$ DSS stimulation for 20 hours. The CD44 cell surface glycoprotein is widely expressed on a variety of cells and is thought to be a major receptor for hyluronic acid, fibronectin, and collagen. ${ }^{25}$ Our adhesion 

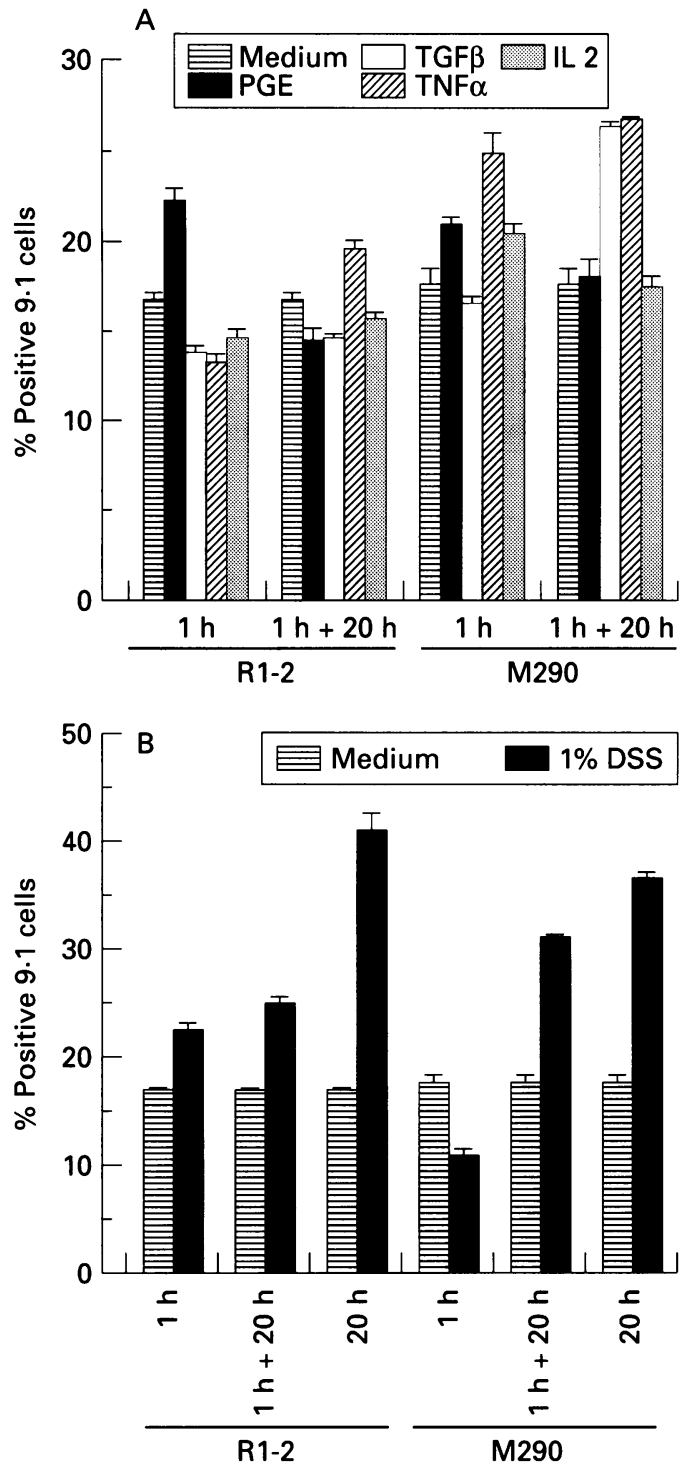

Figure 3: (A) Effect of $P G E_{2}, T G F \beta, T N F \alpha, I L 2$ on $9 \cdot 1$ $\gamma \delta$ IEL hybridoma cell surface expression of the $\alpha 4$ and M290 integrin subunits. 9.1 $\gamma \delta$ IEL hybridoma cells were incubated with either medium, $P G E_{2}(3 \mu M), T G F \beta$ $(5 \mathrm{ng} / \mathrm{ml}), T N F \alpha(100 \mathrm{U} / \mathrm{ml})$ or IL $2(100 \mathrm{U} / \mathrm{ml})$ for one hour in the presence of $m A b s$, and then washed with $P B S$ containing $1 \%$ bovine serum albumin and $0.1 \%$ sodium azide (one hour) prior to FACS analysis. In a separate experiment (designated one hour +20 hours), the cells were incubated with stimuli for one hour, washed, then incubated for a further 20 hours in media. (B) Effect of $D S S$ on the expression of the $\alpha 4$ and M290 integrin subunits. 9.1 $\gamma \delta$ IEL hybridoma cells were incubated with either media or DSS for one hour in the presence of $m A b s$, and then washed with PBS containing $1 \%$ bovine serum albumin and $0 \cdot 1 \%$ sodium azide prior to FACS analysis. In a third experiment (designated 20 hours), cells were incubated with medium containing $1 \%$ DSS for 20 hours, and then washed with PBS containing $1 \%$ bovine serum albumin and $0 \cdot 1 \%$ sodium azide. Finally cells were prepared for FACS analysis by incubation for one hour at $4^{\circ} \mathrm{C}$ with the R1-2 and M290 mAbs. Fluorescence intensities were determined relative to a negative control threshold set by omitting the primary antibody.

studies suggested that CD44 participates in binding of $9.1 \gamma \delta$ to IEC-18 cells. More than $92 \%$ of $9.1 \gamma \delta$ IELH cells expressed CD44 and its expression was only marginally up regulated by TGF $\beta$ and DSS. CD45 receptors are found on all cells of haematopoietic origin, except erythrocytes. ${ }^{26}$ Most $9 \cdot 1 \quad \gamma \delta$ IELH cells expressed CD45 and $50 \%$ of the cells expressed the CD45RB form. Expression of CD45RB on IELH cells was considerably up regulated by DSS and TGF $\beta$ despite the overall expression of CD45 remaining essentially unchanged. When cells were stained with $\mathrm{mAbs}$ in the presence of $0.5 \%$ DSS, the percentage of R1-2 $(\alpha 4)$ and VCAM-1 positive cells was decreased; while the percentage of CD54, CD4, CD45RB, $\alpha M 290$, and 33D1 positive cells was increased and in particular the CD4, CD54, and M290 antigens. The rapid decrease of R1-2 $(\alpha 4)$ and VCAM-1 positive cells when DSS is together with mAbs again suggests that DSS may be perturbing the interaction between mAbs and their antigens. Similarly, the rapid increase of CD54, CD4, CD45RB, $\alpha M 290$, and 33D1 positive cells when DSS was added at the same time with mAbs is in accord with the notion that DSS may increase or block the interaction between $\mathrm{mAbs}$ and their antigens, change the conformation and accessibility of these molecules, or cause translocation and rapid expression of cell surface molecules. The changes in the percentage of positive cells may be the net effect or balance between these different interactions. They seem to depend on the concentration of DSS, as $0.5 \%$ DSS and $1 \%$ DSS have converse effects on the expression of $\alpha 4$ and M290 subunits (compare Fig 3B and Fig 4).

Aggregation of IELH on ECM coated plates in the presence of various concentration of DSS When 9.1 $\gamma \delta$ IELH cells were incubated in empty wells, or in wells coated with ProNectin, poly-L-lysine, fibronectin, and laminin, there was no significant aggregation. Less than $20 \%$ of IELH cells aggregated in the presence of high concentrations of DSS in uncoated wells. However, when $9 \cdot 1 \gamma \delta$ IELH cells were added to ECM coated wells together with various concentrations of DSS, there was a significant dose, time, and ECM type dependent aggregation of the cells. Aggregation occurred after 10 to 15 minutes of incubation and became more pronounced at later time points. The data in the Table represent the aggregation after one hour of incubation. The degree of aggregation decreased in the following order: laminin $>$ poly-Llysine $>$ fibronectin $>$ ProNectin. In ProNectin, poly-L-lysine, fibronectin or laminin coated wells, maximum aggregation was detected at DSS concentrations of $0.2 \%, 0.1 \%, 0.1 \%$, and $0.05 \%$ respectively. There was no significant difference when mAbs to $\alpha 4$ and $\alpha \mathrm{M} 290$ were added to the ECM coated wells together with various concentrations of DSS, suggesting that DSS and ECM induced IELH aggregation was not mediated by either $\alpha 4$ or $\alpha M 290$ subunits of the $\beta 7$ integrin (Table).

Effect of DSS and $m A b$ to the $\alpha M 290$ subunit on adhesion of $9 \cdot 1 \gamma \delta$ IELH cells or epithelial cells to ECM

The data in Fig 5A show the percentage of $9 \cdot 1$ $\gamma \delta$ cells adherent to ECM coated wells. Approximately $36.5 \%, 60.8 \%, 28.2 \%$, and $18.6 \%$ or $9 \cdot 1 \gamma \delta$ cells bound to ProNectin, fibronectin, poly-L-lysine, and laminin coated 


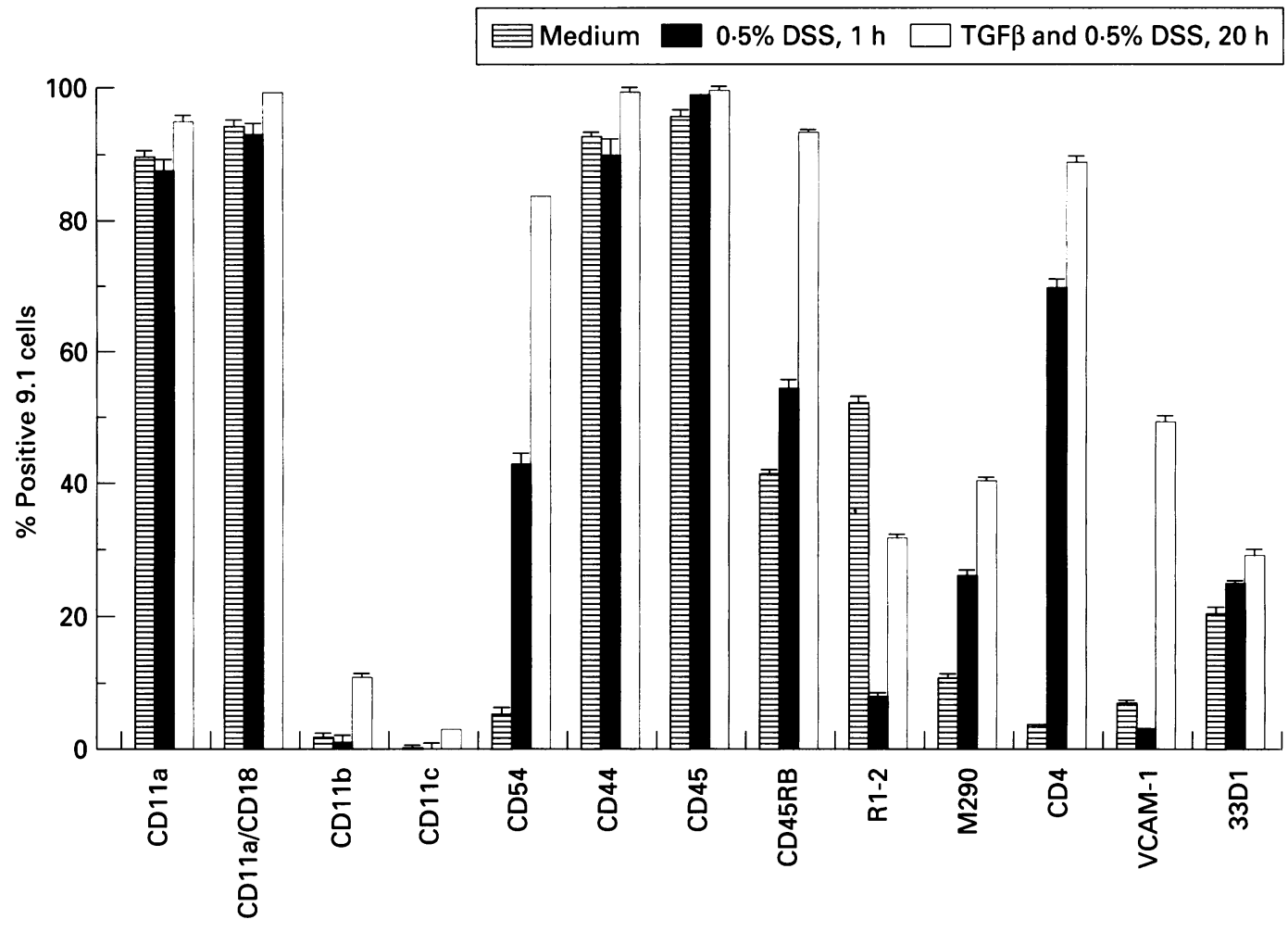

mAbs

Figure 4: Effect of DSS and TGF $\beta$ on the expression of IEL hybridoma $9 \cdot 1$ \% $\delta$ cell surface antigens and cell adhesion molecules. $9 \cdot 1 \gamma \delta$ cells were either left untreated or $0.5 \%$ DSS was included during the one hour incubation staining of cells with $\mathrm{mAbs}$. In a separate experiment cells were treated with a combination of TGF $\beta(5 \mathrm{ng} / \mathrm{ml})$ and $0.5 \% \mathrm{DSS}$ for 20 hours prior to staining cells with $\mathrm{mAbs}$ for 30 minutes at $4^{\circ} \mathrm{C}$. Fluorescence intensities were determined relative to a negative control threshold set by omitting the primary antibody.

plates respectively. The percentage of $9 \cdot 1 \gamma \delta$ cells adherent to fibronectin was greater than the percentage of $\alpha 4$ positive $9 \cdot 1 \gamma \delta$ cells $(16 \%)$ measured at the same time period (Fig 4), suggesting that adhesion of $9 \cdot 1 \gamma \delta$ cells to fibronectin was mediated in part by $\alpha 4 \beta 1$ or $\alpha 4 \beta 7$ receptors, or both. Considerable variation in the adhesion of $9 \cdot 1 \gamma \delta$ to ECM was obtained by including various concentrations of DSS (Fig 5B). DSS inhibited the binding of $9 \cdot 1 \gamma \delta$ to poly-L-lysine and inhibition was decreased by high concentrations of DSS. DSS inhibited the binding of $9 \cdot 1 \gamma \delta$ to laminin at low concentrations, whereas high concentrations of DSS augmented binding. Augmented binding at high concentration of DSS could result from DSS binding to molecules on the cell surface and the ECM, thereby acting as a bridge. DSS inhibited the binding of $9 \cdot 1 \gamma \delta$ to fibronectin and ProNectin at low and mid-concentrations, while high concentrations of DSS stimulated adhesion. There was no significant difference when $\mathrm{mAb}$ to $\alpha \mathrm{M} 290$ was added to laminin, poly-L-lysine, and ProNectin coated wells with various concentrations of DSS, suggesting that laminin, poly-L-lysine, and

Effect of DSS and ECM on aggregation of $9 \cdot 1 \gamma \delta$ IEL hybridomas

\begin{tabular}{|c|c|c|c|c|c|c|c|c|c|}
\hline $\begin{array}{l}\text { DSS (\%) } \\
\text { Plus }\end{array}$ & 0 & 0.0125 & 0.025 & 0.05 & $0 \cdot 1$ & $0 \cdot 2$ & 0.4 & 0.8 & $1 \cdot 6$ \\
\hline Medium & 0 & 0 & 0 & 0 & 0 & 0 & $0 \cdot 3$ & 0.3 & 0.7 \\
\hline ProNectin & 0 & $0 \cdot 7$ & $1 \cdot 0$ & $1 \cdot 3$ & $1 \cdot 7$ & $2 \cdot 0$ & $1 \cdot 7$ & $1 \cdot 3$ & $0 \cdot 3$ \\
\hline Poly-L-lysine & 0 & $1 \cdot 3$ & $2 \cdot 7$ & $3 \cdot 0$ & $3 \cdot 3$ & $2 \cdot 7$ & 2 & $1 \cdot 3$ & $0 \cdot 3$ \\
\hline Fibronectin & 0 & $1 \cdot 3$ & $1 \cdot 7$ & $2 \cdot 7$ & $3 \cdot 7$ & $2 \cdot 3$ & $1 \cdot 3$ & $1 \cdot 0$ & 0.3 \\
\hline Laminin & 0 & $1 \cdot 3$ & $2 \cdot 7$ & 4 & $3 \cdot 7$ & $2 \cdot 7$ & $1 \cdot 3$ & 1 & 0.7 \\
\hline
\end{tabular}

Aggregation is scored as described by Ruegg et al 24 with $0=$ indicating no aggregation, $1=10-20 \%, 2=20-40 \%, 3=40-60 \%, 4=60-80 \%, 5=80-100 \%$ aggregation. Data represent the mean of triplicate experiments.
ProNectin were not the ligands of $\alpha M 290 \beta 7$ integrin (data not shown). However, when the aM290 mAb was added to fibronectin coated wells with various concentrations of DSS, the inhibitory effect of low concentrations of DSS was reversed, as was the stimulatory effect of high concentration of DSS (Fig 5C). It seems by some unknown mechanism that the $\alpha M 290$ $\mathrm{mAb}$ antagonises the effect of DSS on the adhesion of the cells to fibronectin. When IEC-18 cells were added to ECM coated plates together with various concentrations of DSS, DSS inhibited about $50 \%$ of IEC-18 attachment to fibronectin, ProNectin, and poly-Llysine coated plates, while DSS inhibited IEC-18 cell attachment to laminin coated plates by about $20 \%$ only at the highest concentration tested $(0 \cdot 4 \%)$ (Fig $5 \mathrm{D})$.

\section{Discussion}

Our studies provide five important findings with respect to the potential roles of DSS and $\beta 7$ integrin and other cell adhesion molecules in DSS induced colitis. Firstly, DSS exhibits a concentration, time, and cell type dependent cytotoxicity towards intestinal epithelial cells (IEC-18, CMT-93) and IELH cells or fresh IELs. Secondly, the adhesion of IELH to IEC18 or CMT-93 is influenced by DSS, $\mathrm{PGE}_{2}$, TGF $\beta, T N F \alpha$, and IL2. Thirdly, integrin $\alpha 4$ expression is marginally down regulated by TGF $\beta$ and DSS, while $\alpha M 290$ expression is up regulated and the expressions of several other cell adhesion molecules were also affected by DSS. Fourthly, DSS and ECM together induced a significant dose, time, and 

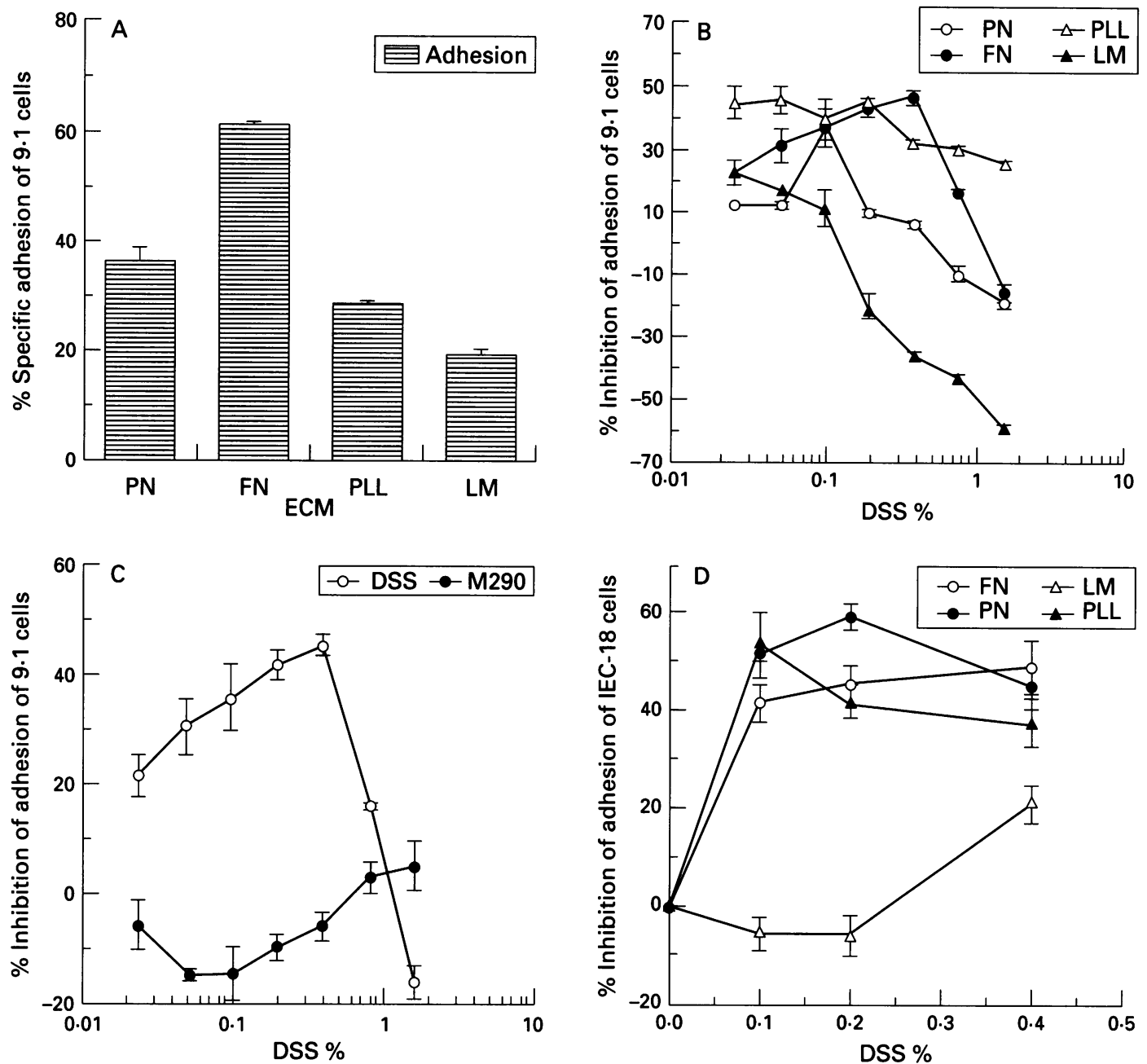

Figure 5: Effect of DSS and the M290 mAb on adhesion of 9.1 $\gamma \delta$ cells or epithelial cells to ECM. (A) Specific adhesion

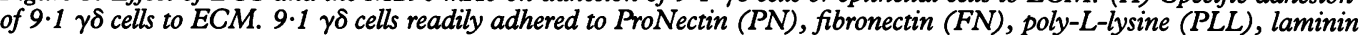

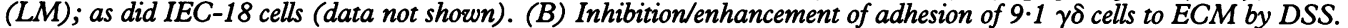
Different concentrations of DSS either inhibited or increased the binding of $9 \cdot 1 \gamma \delta$ cells to ECM depending on the particular ECM. (C) The M290 mAb antagonises the effect of DSS on the binding of $9 \cdot 1 \gamma \delta$ cells to FN. (D) Inhibition of adhesion of IEC-18 cells to ECM. High concentrations of DSS inhibited the binding of IEC-18 cells to fibronectin, ProNectin, laminin, and poly-L-lysine.

ECM type dependent aggregation of mucosal lymphocytes. Finally, in the presence of various concentrations of DSS, the adhesion of $9 \cdot 1$ $\gamma \delta$ IELH cells and IEC-18 epithelial cells to various ECMs was influenced to variable extents by DSS.

The interaction between DSS and the $\beta 7$ integrins can take place at multiple sites. It was suggested that dextran sulphate interact with epidermal growth factor domains or complement regulatory sequence repeats, thereby inducing conformational changes of selectins. ${ }^{17}$ The integrin $\beta 7$ subunit has four cysteine rich epidermal growth factor like repeated domains, which may interact with DSS, although we did not provide direct evidence in this experiment. As $\beta 7$ integrins are candidate receptors for IEL activation, homing, or differentiation and are highly expressed on intestinal lymphocytes in the unique environment of the intestinal mucosa, we propose that $\beta 7$ integrins could be pivotal receptors in the pathogenesis of IBD and cancer development in IBD and that the function of integrin $\beta 7$ receptors could be abnormally modulated by DSS leading to the development of IBD and cancer.

Based on our results and on data in published reports we suggest that DSS induced colitis could be caused by: (a) direct cytotoxicity of DSS; (b) interference of DSS with the normal interaction between IELs, epithelial cells and ECM; (c) modulation of the expression of the integrin $\beta 7$ receptors, other cell receptors, and their functions by DSS.

Our study with DSS induced colitis showed that attenuation, or even prevention in some cases, can be achieved by administration of $\mathrm{mAbs}$ to $\alpha$ subunit of $\beta 7$ integrin receptors, which inhibited the function of $\alpha 4 \beta 7$ and $\alpha M 290 \beta 7$ receptor functions (unpublished). These data supported our hypothesis that integrin $\beta 7$ receptors play an important part in DSS induced colitis in mice.

We wish to thank Dr Mitchell Kronenberg for generously supply us his IELH; Dr Peter Kilshaw for the hybridoma producing $\mathrm{mAb}$ to $\alpha M 290$ (M290); and Immunex for IL2, IL4 IL7.

1 Deusch K, Pfeffer K, Reich K, Gstettenbauer M, Daum S, Luling $\mathrm{F}$, et al. Phenotypic and functional characterization of human TCR gamma delta + intestinal intraepithelial ymphocytes. Curr Top Microbiol Immunol 1991; 173: 279-83

2 Jiang $W-M$, Jenkins $D$, Yuan $Q$, Leung E, Choo KHAC, Watson JD, et al. The gene organization of the human $\beta 7$ subunit, the common $\beta$ su subunit, the common $\beta$ subunit of the leukocyte integrins HML-1 and LPAM-1. Int Immunol 1992; 4: 1031-40. vascular cell adhesion molecule 1 and fibronectin 
Comparison of $\alpha 4 \beta 1$ (VLA-4) and $\alpha 4 \beta 7$ on the human B cell line JY. $\mathcal{B}$ Biol Chem 1992; 267: 8366-70.

4 Parker CM, Cepek KL, Russell GJ, Shaw SK, Posnett DN, Schwarting $\mathrm{R}$, et al. A family of $\beta 7$ integrins on human mucosal lymphocytes. Proc Natl Acad Sci USA 1992; 89: 1924-8.

5 Kilshaw PJ, Murant SJ. Expression and regulation of $\beta 7(\beta \mathrm{p})$ integrins on mouse lymphocytes: relevance to the mucosal integrins on mouse lymphocytes: relevance to the
immune system. Eur $₹$ Immonol 1991; 21: 2591-7.

immune system. Eur F Immonol 1991; 21: 2591-7.
6 Holzmann B, McIntyre BW, Weissman IL. Identification of a murine Peyer's patch-specific lymphocyte homing receptor as an integrin molecule with an alpha chain homologous to human VLA-4 alpha. Cell 1989; 56: 37-46.

7 Schieferdecker HL, Ullrich R, Weiss BA, Schwarting R Stein $\mathrm{H}$, Riecken EO, et al. The HML-1 antigen of intestinal lymphocytes is an activation antigen. $\mathcal{F}$ Immunol 1990; 144: 2541-9.

8 Schieferdecker HL, Ullich R, Zeitz M. Phenotype of HML-1-positive $T$ cells in the human intestinal lamina propria. Immunol Res 1991; 10: 207-10.

9 Schwarting R, Dienemann D, Kruschwitz M, Fritsche G Stein $H$. Specificities of monoclonal antibodies B-ly7 and Stein $H$. Specificities of monoclonal antibodies

10 Cepek KL, Shaw SK, Parker CM, Russell GJ, Morrow JS Rimm DL, et al. Adhesion between epithelial cells and T Rimm DL, et al. Adhesion between epithelial cells and T
lymphocytes mediated by E-cadherin and $\alpha^{\mathrm{E}} \mathrm{b} 7$ integrin. Nature 1994; 372: 190-3.

11 Tamaru T, Kobayashi H, Kishimoto S, Kajiyama G, Shimamoto F, Brown WR. Histochemical study of colonic cancer in experimental colitis of rats. Dig Dis Sci 1993; 38: 529-37.

12 Dorries R, Schimpl A, Wecker E. Action of dextran sulfate as a direct and general B cell mitogen. Eur $\mathcal{F}$ Immunol $1974 ; 4: 230-3$.

13 Minchin SA, Leitenberg D, Stunz LL, Feldbush TL. Polyclonal activation of rat B cells. $\mathcal{F}$ Immunol 1990; 145: 2427-33.

14 Warren HS, Parish CR. Mapping the dextran sulfate binding site on CD2. Immunol Cell Biol 1990; 68: 199-205.

15 Hocking D, Ferro TJ, Johnson A. Dextran sulfate and heparin sulfate inhibit platelet-activating factor-induced pulmonary edema. $\mathcal{F}$ Appl Physiol 1992; 72: 179-85.
16 Skinner MP, Lucas CM, Burns GJ, Hesterman CN, Berndt MC. GMP-140 binding to neutrophils is inhibited by sulfated glycans. $\mathcal{F}$ Biol Chem 1991; 266: 5371-4.

17 Handa $K$, Nudelman ED, Stroud MR, Shiozawa T, Hakomori S. Selectin GMP-140 (CD62, PADGEM) binds to sialosyl-Le $e^{a}$ and sialosyl-Le $e^{x}$, and sulfated glycans modulate this binding. Biochem Biophys Res Commun 1991; 181: 1223-30.

18 Ruoslahti E, Pekkala A, Engvall E. Effect of dextrah sulfate on fibronectin-collagen interaction. FEBS Lett 1979; 107: 51-4.

$19 \mathrm{Ni} \mathrm{J}$, Hollander D. Expression of $\beta 7$ integrins and other cell adhesion molecules on mouse lymphocytes and their modulation by a new cytokine, IL-2 receptor-inducing factor. Cell Immunol 1995; 164: 150-5.

$20 \mathrm{Ni}$ J, Porter AG, Hollander D. $\beta 7$ integrins and other cell adhesion molecules are differentially expressed and modulated by TNF $\beta$ in different lymphocyte populations. Cell Immunol 1995; 161: 166-72.

21 Ni J, Hollander D, Sydora B, Panwala C. Adhesion molecule expression and adhesion properties of murine intestinal intraepithelial lymphocytes hybridomas. Cell Immunol 1995; 164: 156-60.

22 Mosmann T Rapid colorimetric assay for cellular growth and survival: application to proliferation and cytotoxicity and survival: application to proliferation and

$23 \mathrm{Ni} \mathrm{J}$, Meager A, Karpas A. Characterization and partial purification of a novel cytotoxic lymphokine (Factor 2) produced by a human B cell line (Karpas 160). Int Immunol 1992; 4: 519-31.

24 Ruegg C, Postigo AA, Sikorski EE, Butcher EC, Pytela R, Erle DJ. Role of integrin $\alpha 4 \beta 7 / \alpha 4 \beta P$ in lymphocyte adherence to fibronectin and VCAM-1 and in homotypic cell clustering. F Cell Biol 1992; 117: 179-89.

25 Screaton GR, Bell MB, Bell JI, Jackson DG. The identification of a new alternative exon with highly restricted tissue expression in transcripts encoding the mouse Pgp-1 (CD44) homing receptor. F Biol Chem 1993; 268: 12235-8.

26 Pilarski LM, Yacyshyn BR, Jensen GS, Pruski E, Pabst HF. $\beta 1$ integrin (CD29) expression on human postnatal T cell subsets defined by selective CD45 isoform expression. f Immunol 1991; 147: 830-7. 